\title{
MENINGKATKAN KEMAMPUAN BERHITUNG SISWA SD MENGGUNAKAN METODE JARIMATIKA
}

\author{
Syaharuddin ${ }^{1}$, Vera Mandailina ${ }^{2}$ \\ 1,2Pendidikan Matematika, Universitas Muhamadiyah Mataram \\ abialmusthafa@gmail.com ${ }^{1}$, vrmandailina@gmail.com ${ }^{2}$
}

\begin{abstract}
ABSTRAK
Abstrak: Banyak ditemukan terutama di daerah pedalaman para siswa atau anakanak SD kemampuan berhitungnya sangat kurang. Hal ini berbeda dengan di daerah perkotaan atau sekolah-sekolah maju yang sudah menerapkan metode berhitung sangat cepat. Oleh sebab itu, perlu adanya kegiatan dosen di lapangan atau di tengah masyarakat yang membantu anak-anak SD tersebut untuk meningkatkan kemampuan berhitung mereka. Karena kemampuan berhitung ini menjadi dasar perhitungan operasi matematika yang banyak diterapkan di kehidupan sehari-hari. Salah satu metode yang produktif dalam kegiatan ini adalah menggunakan metode jarimatika yang melibatkan organ tubuh siswa sendiri secara langsung, sehingga mampu meningkatkan efisiensi kecepatan berhitung siswa.

Kata Kunci : Kesulitan Berhitung, Jarimatika

Abstract: Many are found especially in rural areas of students or elementary school children whose numeracy is lacking. This is different from in urban areas or advanced schools that have implemented very fast counting methods. Therefore, it is necessary to have lecturers in the field or in the community who help the elementary school children to improve their numeracy skills. Because the ability to count is the basis for calculating mathematical operations that are widely applied in everyday life. One of the productive methods in this activity is using the method of fingerprinting which involves the student's own body organs directly, so as to improve the efficiency of student's numeracy speed.
\end{abstract}

Keywords: Difficulty Counting, Jarimatika.

Riwayat Artikel: Diterima: 2 Desember 2017, Disetujui: 17 Januari 2018 


\section{A. PENDAHULUAN}

\section{Situasi Mitra Kegiatan}

Keberhasilan pendidikan di sebuah sekolah ditentukan oleh kualitas lulusan para peserta didik. Sehingga berbagai metode pembelajaran diterapkan agar kualitas tersebut meningkat secara signifikan. Salah satu mata pelajaran yang menjadi penentu keberhasilan perserta didik adalah matematika. Dalam pembelajaran matematika kita kenal dengan istilah berhitung. Proses berhitung ini merupakan kunci dari konsep atau kemampuan yang lain, baik secara langsung maupun tidak langsung.

Peserta didik dengan kemampuan berhitung tinggi atau cepat sangat membantu dalam proses penyelesaian soal-soal matematika, begitu juga sebaliknya, siswa dengan kemampuan berhitung lambat cendrung akan lambat dalam menyelesaikan persoalan matematika. Oleh sebab itu, kemampuan berhitung siswa menjadi sorotan utama di setiap tingkatan (kelas), bahkan kemampuan ini sudah mulai ditanamkan sejak sebelum masuk sekolah.

Satu sisi, perkembangan teknologi terkadang membuat kita manja untuk berhitung menggunakan kemampuan otak kita dan lebih menggunakan alat bantu, sementara pada saat ujian sekolah setiap siswa dilarang menggunakan alat bantu tersebut. Dimana kemampuan berhitung ini wajib ditanamkan saat masih di bangku Sekolah Dasar (SD).

Berdasarkan hasil obseravsi di Desa Loang Maka, khususnya di Dusun Tibu Sisok terdapat banyak siswa SD yang berkemampuan kurang dalam berhitung. Hal ini terlihat dari beberapa soal matematika yang secara kebetulan kami tanyakan, ternyata masih banyak siswa yang tidak bisa menjawab, kalaupun bisa menjawab tapi sangat lambat bahkan ada yang sampai salah jawaban.

Kemudian di beberapa Sekolah Menengah Pertama (SMP) di daerah Desa Loang Maka tidak luput dari observasi kami untuk melihat kemampuan berhitung siswa, ternyata masih terdapat juga siswa yang kemampuannya masih di bawah rata-rata, mereka sangat lambat dalam menjawab meskipun itu perhitungan biasa, oleh sebab itulah factor utama dalam masalah ini adalah kemampuan berhitung yang lambat dan kami mengusulkan untuk melakukan pengabdian kepada masyarakat dalam bentuk "Peningkatan Kemampuan Berhitung Siswa SD Menggunakan Metode Jarimatika".

\section{Lokasi Pengabdian}

Tim Pelaksana bekerja sama dengan OSIS SMP Ibadurrahman serta guru matematika yang ada disana. Sehingga pelaksanaan kegiatan ini berlangsung di PP. Ibadurrahman. Sedangkan para siswa dari berbagai SD seperti SDN 1, SDN 2, dan SDN 3 Tibu Sisok datang ke lokasi pengabdian yakni di PP. Ibadurrahman Dusun Tibu Sisok Desa Loang Maka Kecamatan Janapria Lombok Tengah.

\section{B. METODE PELAKSANAAN KEGIATAN}

Prosedur pelaksanaan pengabdian masyarakat ini merupakan pelatihan peningkatan kemampuan berhitung siswa SD menggunakan metode jarimatika, dengan Dosen Prodi Matematika UM Mataram sebagai pengajar atau pelatih dan dibantu oleh beberapa guru matematika di Desa Loang Maka dan mahasiswa KKN. Adapun prosedur pelaksanaannya sebagai berikut:

1. Konfirmasi kepada para guru matematika SD dan SMP di Desa Loang Maka Lombok Tengah.

2. Konfirmasi kepada pihak Yayasan PP Ibadurrahman sebagai lokasi utama pelatihan metode jarimatika.

3. Menyepakati jadwal pelatihan dengan pihak sekolah. 
4. Bersurat kepada masing-masing kepala sekolah untuk mengirim siswa kelas 5 - 6 untuk mengikuti pelatihan metode jarimatika yang berpusat di PP Ibadurrahman.

5. Menyiapkan lokasi, perlengkapan, dan segala kebutuhan selama pelatihan.

Melaksanakan pelatihan sesuai dengan jadwal yang telah susun dan disepakati.

\section{HASIL DAN PEMBAHASAN}

\section{Waktu Efektif Pelaksanaan}

Pengabdian ini dilaksanakan selama 3 bulan (Maret-Mei 2017). Setelah melakukan konfirmasi ke sekolah, membuat jadwal, menyusun materi, bersurat ke tiap SDN sampai menyiapkan lokasi pelatihan kurang lebih 3 bulan. Maka dilakukanlah pelatihan jarimatika di Aula/Musholla PP Ibadurrahman. Namun waktu efektif pelaksanaan pengabdian ini dilakukan selama 1 minggu pada tanggal. Adapun prosedur pelaksanaan pelatihan metode jarimatika, yakni:

TABEL 1.

RINCIAN PELAKSANAAN KEGIATAN

\begin{tabular}{|c|l|l|}
\hline Hari & \multicolumn{1}{|c|}{ Kegiatan } & \multicolumn{1}{|c|}{ Pelatih / PJ } \\
\hline Ke-1 & Registrasi Peserta dan Tes Awal & Mahasiswa KKN \\
\hline Ke-2 & Pelatihan Level 1 & Guru SMP Ibadurrahman \\
\hline Ke-3 & Pelatihan Level 2 & $\begin{array}{l}\text { Vera Mandailina, M.Pd } \\
\text { \& Mahasiswa KKN }\end{array}$ \\
\hline Ke-4 & Pelatihan Level 3 & $\begin{array}{l}\text { Syaharuddin, M.Si } \\
\text { \& Mahasiswa KKN }\end{array}$ \\
\hline Ke-5 & Pelatihan Level 4 & $\begin{array}{l}\text { Syaharuddin, M.Si } \\
\text { \& Mahasiswa KKN }\end{array}$ \\
\hline Ke-6 & Pelatihan Level 5 & $\begin{array}{l}\text { Syaharuddin, M.Si } \\
\text { \& Mahasiswa KKN }\end{array}$ \\
\hline Ke-7 & Evaluasi & $\begin{array}{l}\text { Vera Mandailina, M.Pd } \\
\& \text { Mahasiswa KKN }\end{array}$ \\
\hline
\end{tabular}

Adapun hasil evaluasi hasil siswa seperti Tabel 2 di bawah ini.

TABEL 2

HASIL EVALUASI SISWA

\begin{tabular}{|c|l|c|}
\hline No & \multicolumn{1}{|c|}{ Nama } & Nilai \\
\hline 1 & Yayang Okta Prayitna & 76 \\
\hline 2 & Luluk Anggraini & 86 \\
\hline 3 & Pina Agustina & 79 \\
\hline 4 & Rentin Putri Suli Mekar & 89 \\
\hline 5 & Natalia Julia Ningsih & 90 \\
\hline 6 & Lara Kartika & 98 \\
\hline 7 & Ida Rahmawati & 96 \\
\hline 8 & Marliana & 80 \\
\hline 9 & Kavin Arkazila & 86 \\
\hline 10 & Suci Anggraini & 88 \\
\hline 11 & Intan Komala Sari & 67 \\
\hline 12 & Nurhasanah & 87 \\
\hline 13 & Selistia Putri & 76 \\
\hline 14 & Gea Astiananta & 87 \\
\hline 15 & Azira Orviana & 89 \\
\hline 16 & Laura Amelia Agustin & 90 \\
\hline 17 & Jelita Meilisya Agustin & 87 \\
\hline 18 & Narva Meisya Putri & 86 \\
\hline
\end{tabular}




\section{Konstribusi Mitra Dalam Kegiatan}

Konstibusi Mitra selama kegiatan sangat dirasakan oleh tim pengabdian. Mulai sejak kesepakatan pelaksanaan, distribusi informasi, maupun penyiapan lokasi pelaksanaan. Informasi disebarkan oleh pengurus OSIS dan pengurus Pondok Pesantren lainnya bahwa akan dilakukan pelatihan jarimatika. Di samping itu, pihak sekolah (SD) juga menginformasikan para siswa untuk datang pada saat pelatihan. Di sisi lain, pengurus pondok beserta OSIS juga menyipakan lokasi pelatihan. Sehingga sangat dirasakan kebersamaan dalam bentuk konstribusi mitra dalam kegiatan pengabdian ini.

\section{Potret Permasalahan Lain yang Terekam}

Tahap awal diketahui bahwa sebagian besar siswa SD di Desa Loang Maka khususnya di Dusun Tibu Sisok Lombok Tengah berkamampuan kurang dalam berhitung di bidang matematika. Ketika kami memberikan soal-soal dalam kontek berhitung, rata-rata siswa terdiam tidak bisa menjawab, jikapun di antara mereka ada yang menjawab masih tergolong lambat, sementara kemampuan berhitung menjadi kunci untuk menyelesaikan persoalan matematika yang lain. Kemudian kondisi ini sangat memperihatinkan karena pada mata pelajaran matematika untuk operasi aritmatika sangat kurang khususnya di bagian perkalian. Di samping itu, karena konsep dasar penjumlahan yang masih kurang maksimal.

\section{PENUTUP}

\section{Simpulan}

Berdasarkan hasil pelaksanaan dan evaluasi diperoleh kesimpulan bahwa:

a. Pelatihan Jarimatika sangat bermanfaat dan membantu dalam peningkatan kemampuan berhitung siswa.

b. Terjadi peningkatan kemampuan berhitung sebesar $34,4 \%$, hal ini dapat dilihat dari hasil tes awal dan tes akhir yakni rata-rata awal kemampuan

2. Saran siswa sebesar 64, sedangkan setelah pelatihan rata-rata sebesar 86 .

Berdasarkan hasil pengabdian ini, kami bisa memberikan saran untuk kegiatan pengabdian selanjutnya, yakni:

a. Dana Pengabdian sebaiknya ditingkatkan agar kegiatan ini bisa dilakukan dengan jangka waktu yang lebih lama, lokasi yang luas, dan jumlah siswa yang banyak.

b. Pihak guru khususnya guru matematika untuk tetap melestarikan konsep perhitungan Jarimatika agar kemampuan berhitung siswa bisa meningkat dari generasi ke generasi.

\section{DAFTAR PUSTAKA}

Afifuddin dan Beni A. S. 2009. Metode Penelitian Kualitatif. Bandung: Pustaka Setia

DP2M Dikti. Buku Panduan Pelaksanaan Penelitian dan Pengabdian Kepada Masyarakat Edisi XI Tahun 2017. Jakarta, 2017.

LPM UM Mataram. Pedoman Pengabdian Kepada Masyarakat dan Prosedur Penulisan Proposal. Universitas Muhammadiyah Mataram, 2017.

Sugihastuti. 2014. Bahasa Laporan Penelitian. Yogyakarta: Pustaka Pelajar Offset 